\title{
Comparison between Distractor Application on Both Radial \& Ulnar Side and Radial Side Only for Fracture Distal Radius with Ulnar Styloid Fracture
}

\author{
Ujjal Bhakat $^{1}$, Arindam Mukherjee ${ }^{2}$, Ranadeb Bandyopadhyay ${ }^{3}$ \\ ${ }^{1}$ B. S. Medical College, Bankura, India; ${ }^{2}$ The Mission Hospital, Durgapur, India; ${ }^{3}$ Department of Orthopaedics, B. S. Medical Col- \\ lege, Bankura, India. \\ Email: ujjal_doc@yahoo.com
}

Received June $28^{\text {th }}$, 2013; revised July 29 ${ }^{\text {th }}, 2013$; accepted August $14^{\text {th }}, 2013$

Copyright (C) 2013 Ujjal Bhakat et al. This is an open access article distributed under the Creative Commons Attribution License, which permits unrestricted use, distribution, and reproduction in any medium, provided the original work is properly cited.

\begin{abstract}
Background: Fracture of distal radius with involvement of the ulnar styloid process is a common clinical problem. It can be treated conservatively, usually involving wrist immobilization in plaster cast or surgically. A key method of surgical fixation is external fixation by distractor. Distractor can be applied either only on the radial side or on both ulnar and radial sides. Materials and Methods: A prospective randomized and comparative study of 1 year duration was conducted on 32 patients admitted in the Department of Orthopaedics of BSMC \& H in the age group of 20 to 75 years old with AO types B and C distal radius fracture along with involvement of the ulnar styloid process. The parameters studied were restoration of radial length, restoration of radial angle, intracarpal step-off and palmar tilt which were statistically evaluated and Fisher's exact test was performed. The two tailed P-value was calculated and both the groups were statistically compared. Results: In our study, 37.5\% patients in Group A and 81.25\% in Group B had a radial difference $<3 \mathrm{~mm}$ which was statistically significant (Table 1, Chart 1). 43.75\% patients in Group A and 87.5\% in Group B had radial angle $<5$ ' which was significant (Table 2, Chart 2). 31.25\% in Group A and 75\% had intra carpal step off $<2 \mathrm{~mm}$ which was again statistically significant (Table 3, Chart 3). $62.5 \%$ had an abnormal palmar tilt in Group A while only $6.25 \%$ had an abnormal palmar tilt in Group B which is extremely statistically significant. On an average, 2 $\mathrm{mm}$ of distraction was required in 75\% patients of Group A while only 30\% patients in Group B required distraction (Table 4, Chart 4). Conclusion: In our study, the radial difference, radial angle, intra carpal step off and palmar tilt returned significantly to normal in the patients treated with distractor on radial side only when compared with distractor application on both radial and ulnar sides for distal radius fracture with ulnar styloid process involvement. Also post-operative distraction required under image intensifier was higher in the group treated with distractor on either side than those with distractor only on radial side.
\end{abstract}

Keywords: Fracture Distal Radius; Plaster Cast; Distractor; Radial Length; Radial Angle; Intra Carpal Step Off; Palmar Tilt; Fischer's Test; P-Value

\section{Introduction}

The incidence of distal radius fracture with ulnar styloid fracture is increasing together with average age of population. Intra-articular incongruity is the most probable cause of unsatisfactory outcome of these fractures in younger and most active adults. Thus the main goal in the treatment should be restoration of articular congruence. Persistent intra-articular incongruity has been shown to cause a 9.9 fold increased risk of radiological osteoarthritis and restriction of range of motion $[1,2]$.

New implants have been designed to provide stable and enough fixations for early mobilization after surgery and to lower complication rates, such as external fixation by distractor and internal fixation by Allie's plate. Distal radius fracture along with involvement of the ulnar styloid, closed or open, can be treated by distractor application on the radial side only. It can also be treated by application of distractor on both the radial and ulnar sides of the affected forearm [3].

Hence we conducted a study in our rural set up to compare the results of treatment of these fractures by external fixation with a distractor by either of the two methods. 


\section{Materials and Methods}

A prospective randomized and comparative study was conducted on the patients admitted in the Department of Orthopaedics of BSMC \& H. Our study population mainly consisted 32 patients (16 in each group) aged between 20 to 75 years old, of either sex with distal radius intra-articular fracture (AO types $\mathrm{B}$ and $\mathrm{C}$ ), along with involvement of the ulnar styloid process. The study period was about 1 year from October 2010 to September 2011. Eligibility criteria for the patients included in the study were as follows: 1 ) Patients who were in the age group of 20 to 75 years of either sex, 2) distal radius intra-articular fracture along with involvement of the ulnar styloid process without any systemic or psychiatric illness, 3) patients fit for anaesthesia.

The parameters studied were radiographic parameters: 1) Restoration of radial length (within $3 \mathrm{~mm}$ of contralateral side), 2) restoration of radial angle ( $<5$ degrees), 3 ) intracarpal step-off $(<2 \mathrm{~mm})$ and 4$)$ palmar tilt $(0$ degrees).

After obtaining ethical clearance from the institutional Ethics committee, study was conducted among the study populations after obtaining written informed consent in accordance with the Ethical standards of the 1964 Declaration of Helsinki as revised in 2000. The relevant information collected by using a pre-designed proforma including history, general and systemic examination findings. Initial radiograph of the wrist joint was conducted besides routine pre anesthetic investigations. The $32 \mathrm{pa}-$ tients were divided in to two groups, 16 in each. The patients under group A were treated by distractor application on both the radial and ulnar sides, while group $\mathrm{B}$ were treated with distractor application on the radial side only. The patients were followed up with radiographs at 2 weeks apart. Distraction was done in only those with persistent deformity under image intensifier. The distractor was maintained for 6 weeks on an average till bony union was evident on skiagram. Following removal of the distractor, the patients were advised active and passive range of motion exercises of the wrist joint. Patients were followed up at every 2 weeks. Radiographs were obtained again at the end of 12 weeks for comparison. The number of patients with restoration of radial length (within $3 \mathrm{~mm}$ of the contralateral side), radial angle $(<5$ degrees), intracarpal step-off $(<2 \mathrm{~mm})$ and palmar tilt (0 degrees) in each group were evaluated and Fisher's exact test was performed. The two tailed P-value was calculated and both the groups were statistically compared.

\section{Results}

The 32 patients under the study were divided into 2 groups (16 in each).

Group A-distractor application on both the radial and ulnar side of the forearm (Figures 1-5).

Group B-distractor application on the radial side of the forearm only (Figures 6-10).

In both Groups A and B, 10 were males and 6 were females.

In either groups, 9 were $\mathrm{AO}$ type $\mathrm{B}$ and 7 were $\mathrm{AO}$ type C.

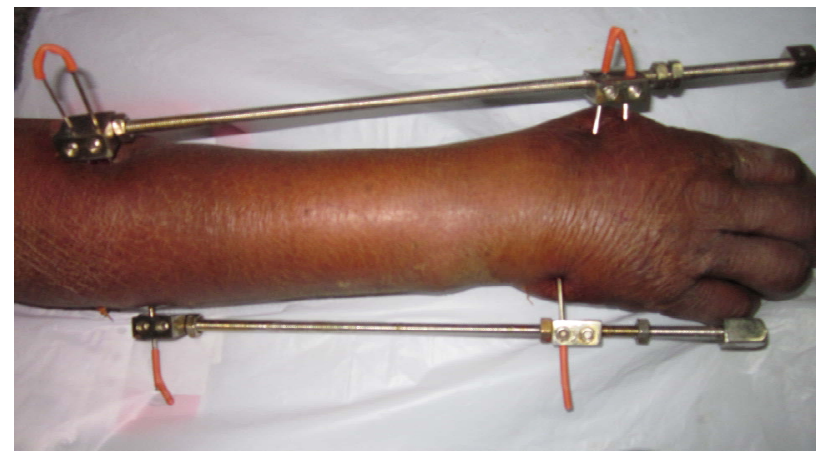

Figure 1. Post operative clinical photograph of distractor application on both radial \& ulnar side.

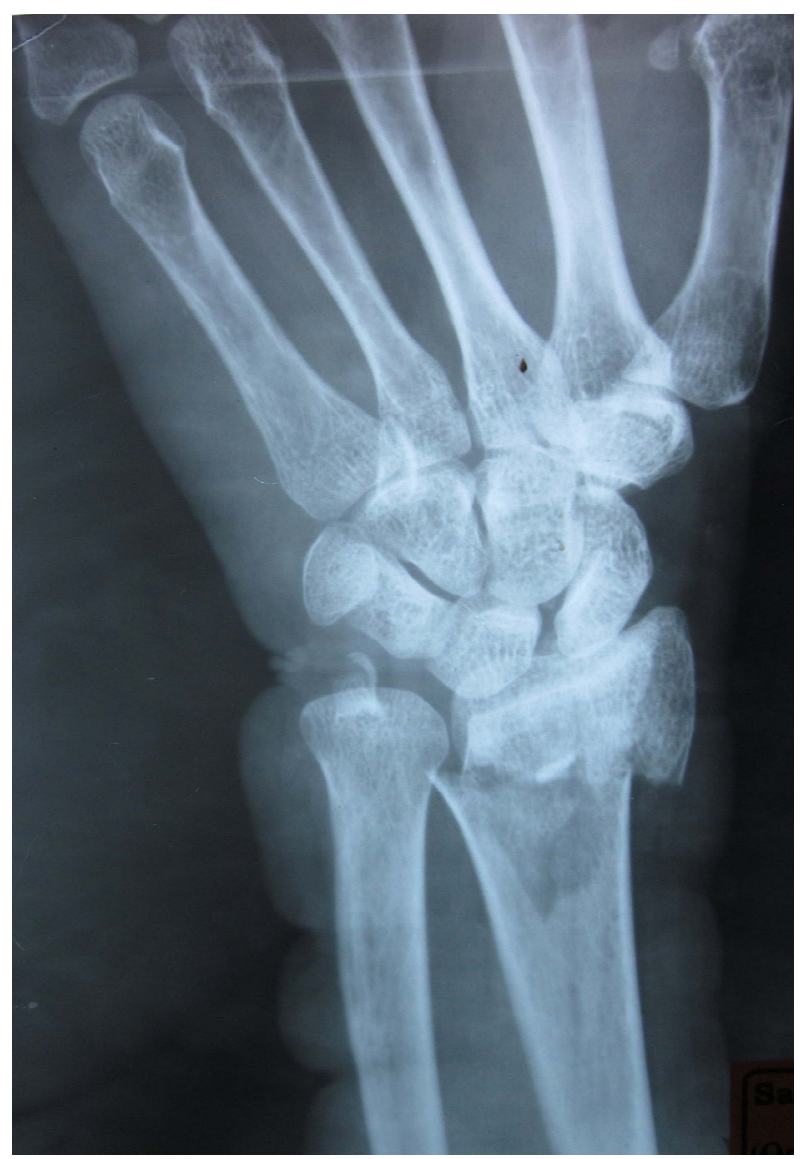

Figure 2. Pre-operative skiagram of wrist showing forearm A-P view. 


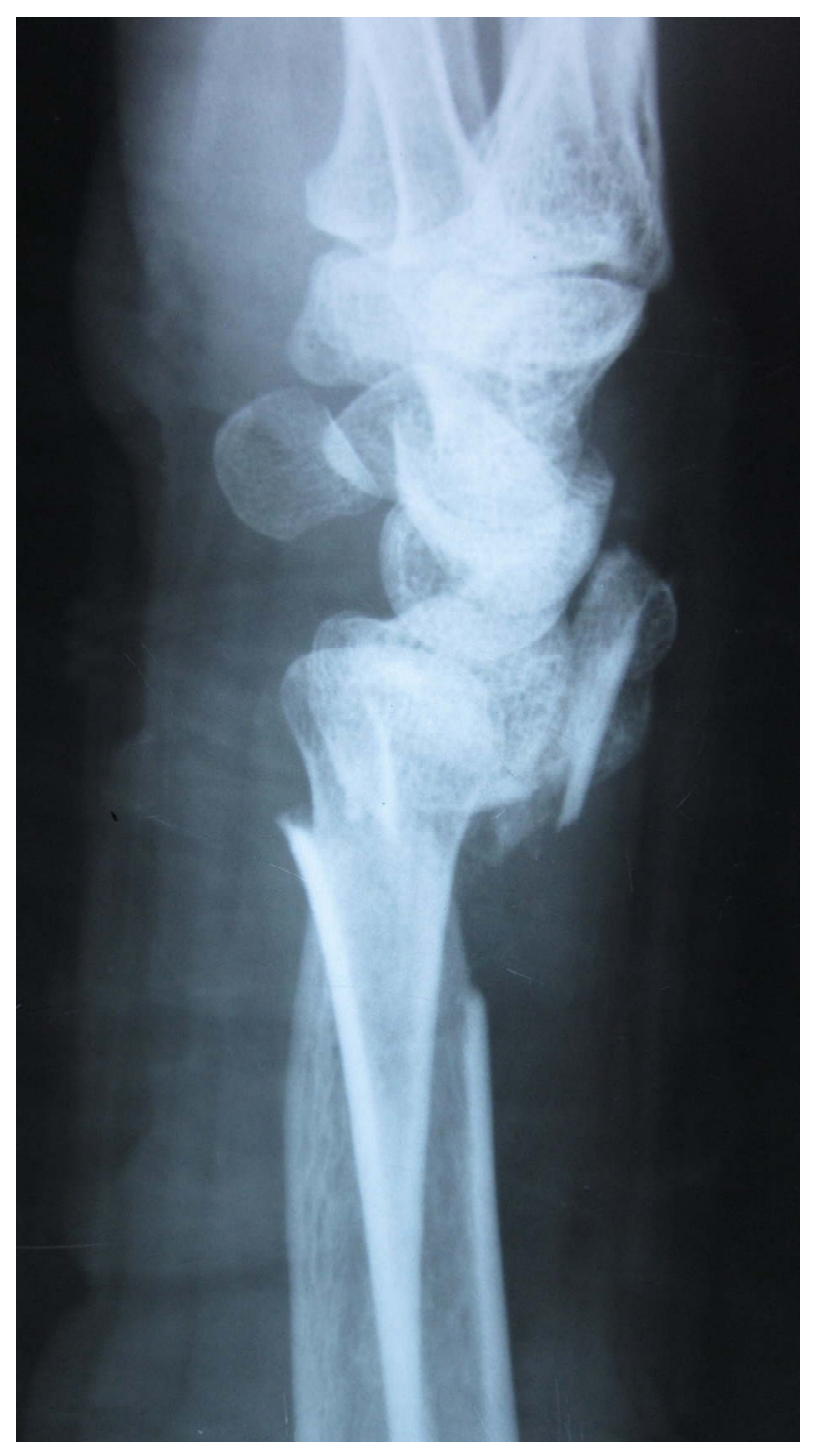

Figure 3. Pre-operative skiagram of wrist showing forearm lateral view.

The results were statistically analyzed using Fisher's exact test and the two tailed $\mathrm{P}$ value was evaluated.

In our study, 37.5\% (6 of 16) patients in Group A had a radial difference $<3 \mathrm{~mm}$ while $62.5 \%$ (10 of 16) had radial difference $>3 \mathrm{~mm}$. In Group B, 81.25\% (13 of 16) had a radial difference $<3 \mathrm{~mm}$ whereas $18.75 \%$ (3 of 16) had a difference $>3 \mathrm{~mm}$ which was significant (P-value 0.0290) (Table 1, Chart 1). 43.75\% (7 of 16) patients had radial angle $<5$ ' while $56.25 \%$ (9 of 16 ) had radial angle $>5$ ' in Group A. In Group B, 87.5\% (14 of 16) had radial angle $<5$ ' while $12.5 \%$ (2 of 16 ) had $>5$ ' which was significant (P-value 0.0233) (Table 2, Chart 2). $31.25 \%$ (5 of 16) had intra carpal step off $<2 \mathrm{~mm}$ and $68.75 \%$ (11 of 16) had step off $>2 \mathrm{~mm}$ in Group A. In Group B, 75\% (12 of 16) had intra carpal step off $<2 \mathrm{~mm}$ while $25 \%$ (4 of 16) had step off $>2 \mathrm{~mm}$ which was

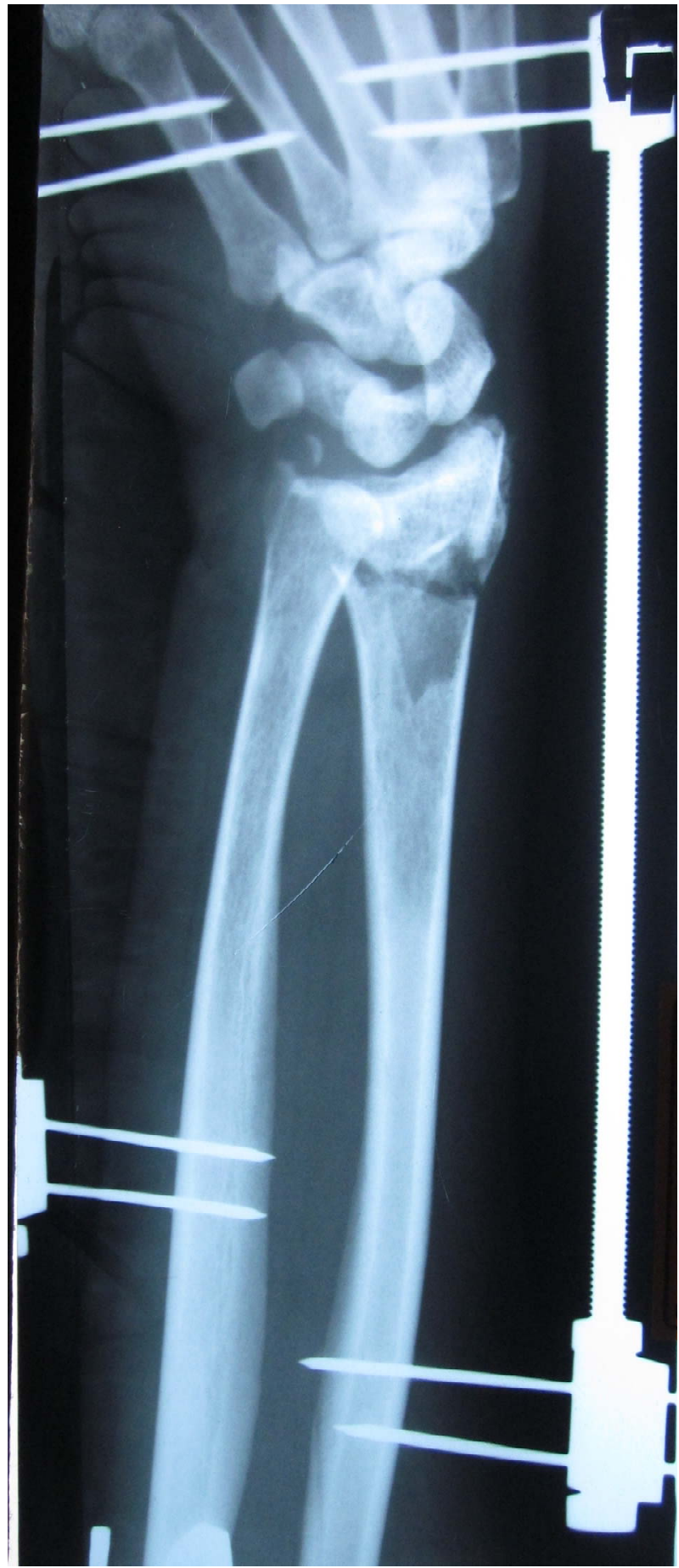

Figure 4. Post operative skiagram of wrist showing forearm with distractor on both radial and ulnar side A-P view.

again significant statistically (P-value 0.0320) (Table 3, Chart 3). $62.5 \%$ (10 of 16) had an abnormal palmar tilt in Group A while only 6.25\% (1 of 16) had an abnormal palmar tilt in Group B which is extremely statistically significant (P-value 0.0021) (Table 4, Chart 4).

In our study, on an average $2 \mathrm{~mm}$ of distraction was 


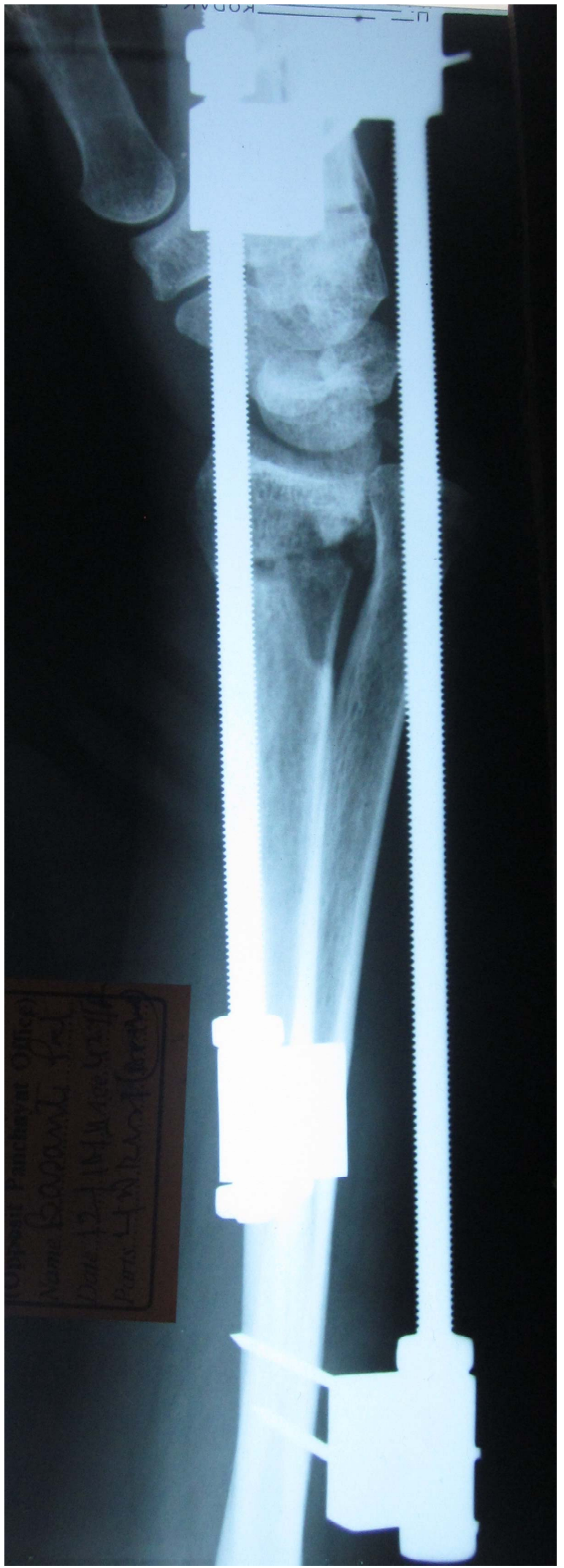

Figure 5. Post operative skiagram of wrist showing forearm with distractor on both radial and ulnar side lateral view.

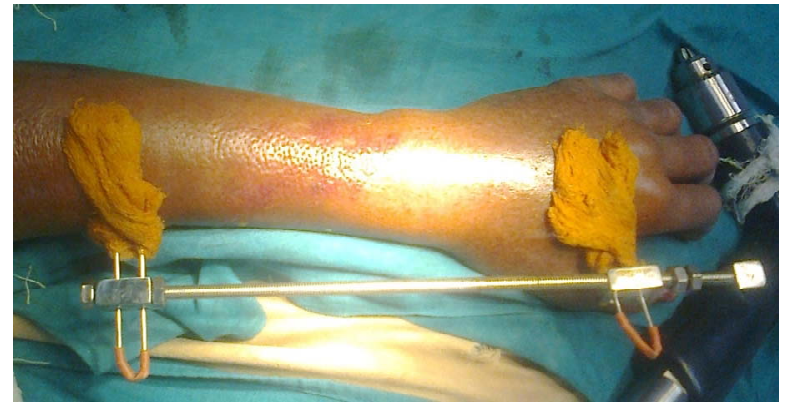

Figure 6. Post operative clinical photograph of distractor application on radial side.

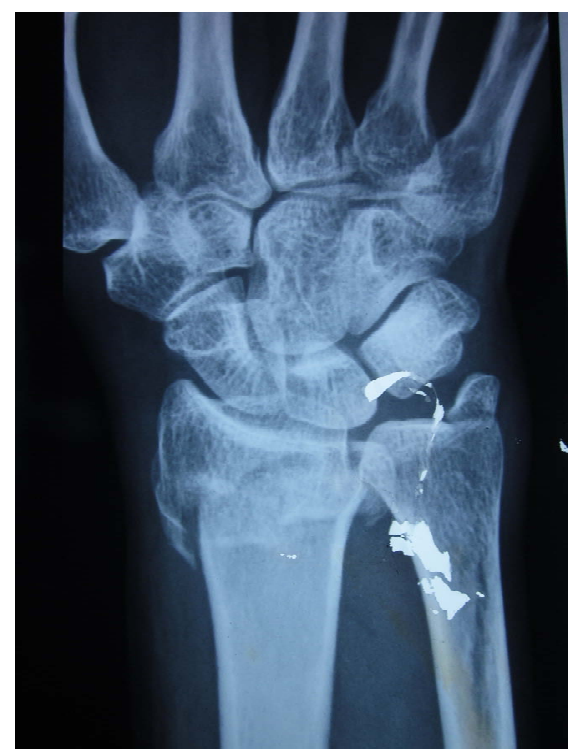

Figure 7. Pre-operative skiagram of wrist showing forearm A-P view.

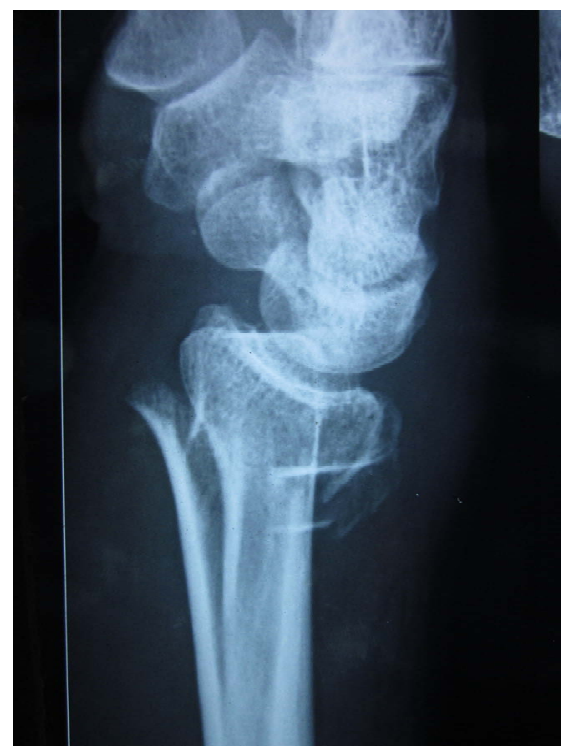

Figure 8. Pre-operative skiagram of wrist showing forearm lateral view. 


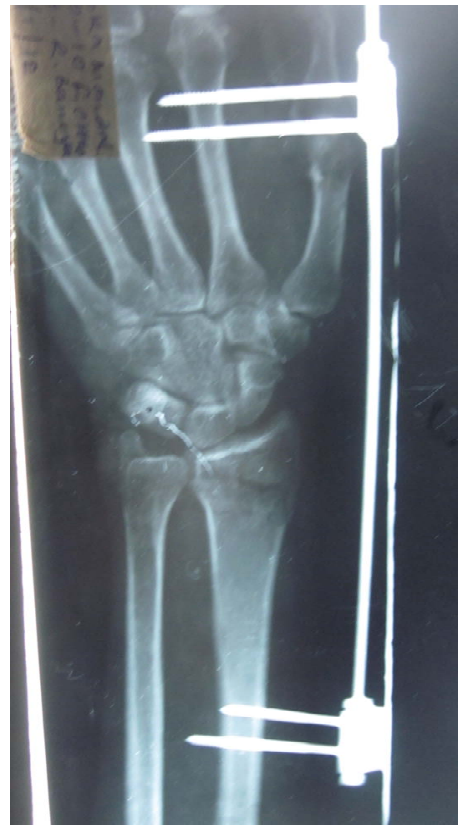

Figure 9. Post operative skiagram of wrist showing forearm with distractor on radial side A-P view.

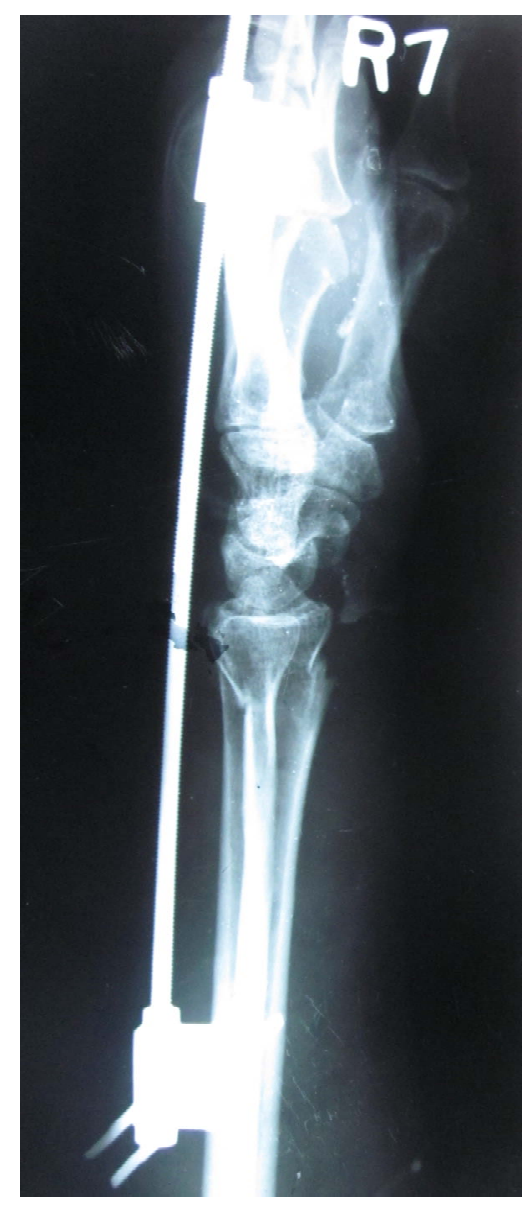

Figure 10. Post operative skiagram of wrist showing forearm with distractor on radial side lateral view.
Table 1. Restoration of radial length.

\begin{tabular}{lccc}
\hline & $\begin{array}{c}\text { Radial length } \\
\text { difference }<3 \mathrm{~mm}\end{array}$ & $\begin{array}{c}\text { Radial length } \\
\text { difference }>3 \mathrm{~mm}\end{array}$ & P-value \\
\hline Group A & 6 & 10 & 0.0290 \\
Group B & 13 & 3 & \\
\hline
\end{tabular}

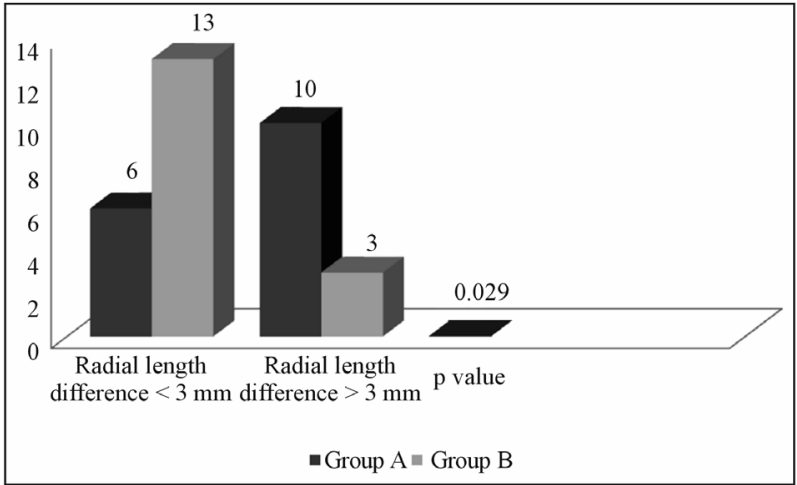

Chart 1. Restoration of radial length to within $3 \mathrm{~mm}$ of contra-lateral normal side.

Table 2. Radial angle.

\begin{tabular}{cccc}
\hline & Radial angle $<5$, & Radial angle $>5$, & P-value \\
\hline Group A & 7 & 9 & \\
Group B & 14 & 2 & 0.0233 \\
\hline
\end{tabular}

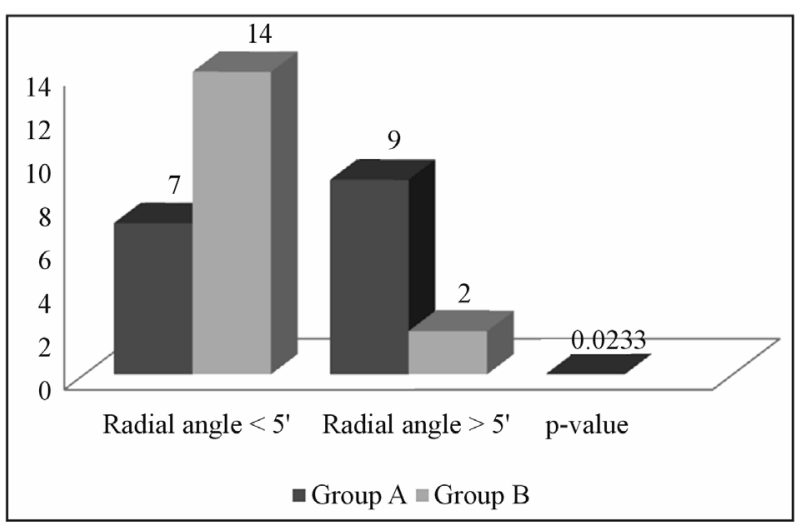

Chart 2. Restoration of radial angle to $<5$ degrees.

required in $75 \%$ patients of Group A while only 30\% patients in Group B required distraction.

\section{Discussion}

Fracture of distal radius along with fracture ulnar styloid process usually is classified as either extra-articular or intra-articular. Numerous eponyms are applied to fractures in this region [2]. The most used AO classification divides distal radius fractures in three groups and three 
Table 3. Intra-carpal step off.

\begin{tabular}{lccc}
\hline & $\begin{array}{c}\text { Intra-carpal } \\
\text { step off }<2 \mathrm{~mm}\end{array}$ & $\begin{array}{c}\text { Intra-carpal } \\
\text { step off }>2 \mathrm{~mm}\end{array}$ & P-value \\
\hline Group A & 5 & 11 & 0.0320 \\
Group B & 12 & 4 & \\
\hline
\end{tabular}

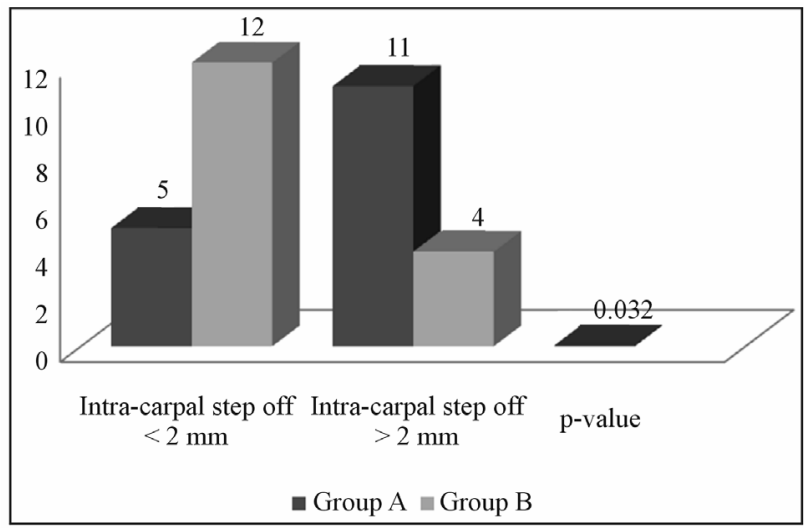

Chart 3. Intra-carpal step off.

Table 4. Palmar tilt.

\begin{tabular}{lccc}
\hline & $\begin{array}{c}\text { Normal palmar tilt } \\
\text { (0 degree ) }\end{array}$ & $\begin{array}{c}\text { Abnormal } \\
\text { palmar tilt }\end{array}$ & P-value \\
\hline Group A & 6 & 10 & 0.0021 \\
Group B & 15 & 1 & \\
\hline
\end{tabular}

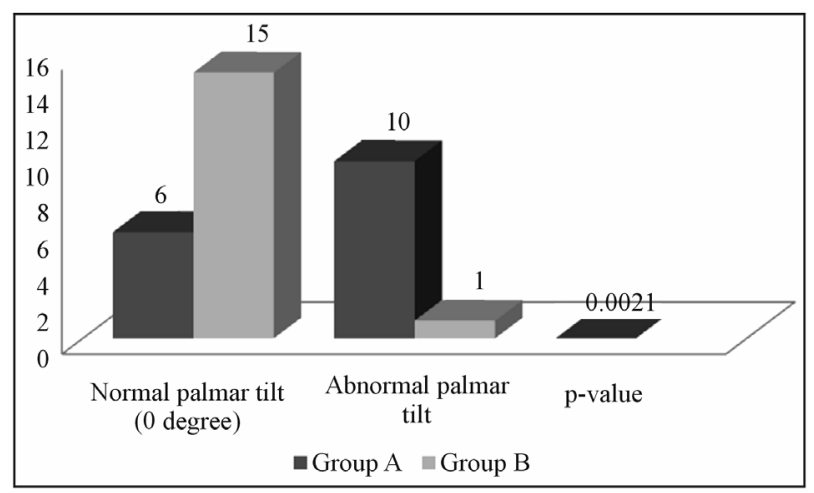

Chart 4. Palmar tilt.

subgroups. Groups A1-3 include extra-articular fractures, Groups B1-3 include partly intra-articular fractures such as volar and dorsal Barton fractures and Groups C1-3 include completely intra-articular fractures [4]. 76\% to 91\% of fractures of young adults with residual intra-articular incongruity showed arthritis 7 years after the injury compared to $11 \%$ of fractures with congruous joint.

Dorsal angulation of radiocarpal joint surface worsens functional outcome considerably when it exceeds 20 degrees [3]. 38 years after the injury, each ten degrees of dorsal angulation diminishes volar flexion by three degrees [4]. Dorsal angulation exceeding 20 degrees caused a 6 and 8 degrees loss of volar flexion 3 and 7 years after the injury respectively [4-7]. Radial shortening of more than $4 \mathrm{~mm}$ associates with decreased forearm rotation at 3 years follow-up [8,9].

So the main goal of treatment is to maintain the articular congruity and anatomical restoration of fracture site by different methods of treatment like external fixation by distractor or by conservative methods. This study compares the result outcome of treatment of distal radius fracture by distractor application on both radial and ulnar sides of the forearm and distractor application on only radial side of the forearm [10].

In our study, 37.5\% patients in Group A had a radial difference $<3 \mathrm{~mm}$ while in Group B 81.25\% had a radial difference $<3 \mathrm{~mm}$ which was statistically significant (Table 1, Chart 1). $43.75 \%$ patients had radial angle $<5$ ' in Group A while in Group B, 87.5\% had radial angle $<5$ ' which was significant (Table 2, Chart 2). 31.25\% had intra carpal step off $<2 \mathrm{~mm}$ in Group A. In Group B, $75 \%$ had intra carpal step off $<2 \mathrm{~mm}$ which was again statistically significant (Table 3, Chart 3). 62.5\% had an abnormal palmar tilt in Group A while only $6.25 \%$ had an abnormal palmar tilt in Group B which is extremely statistically significant (Table 4, Chart 4). On an average, $2 \mathrm{~mm}$ of distraction was required in $75 \%$ patients of Group A while only 30\% patients in Group B required distraction.

In conclusion, the results of distractor application for intra articular distal radius fracture (AO types B and C) with ulnar styloid involvement on radial side alone are better than application on both radial \& ulnar sides. Furthermore, it is seen that on application of distractor on either sides of a forearm, there is a chance of collapse of the radial fracture fragment. This is probably due to ulnar stretching that distorts the normal anatomical relation between the two styloids (i.e., the radial styloid being at a lower level compared to the ulnar styloid). Also, only $30 \%$ patients with distractor on radial side required repeat distraction at 2 weeks whereas $75 \%$ patients with distractor on both sides necessitated distraction.

Hence distractor applied on radial side only is superior, less costly as well as less cumbersome to distractor applied on both radial and ulnar sides.

\section{REFERENCES}

[1] J. T. Capo, W. Rossy, P. Henry, R. J. Maurer, S. Naidu and L. Chen, "External Fixation of Distal Radius Fractures: Effect of Distraction and Duration," Journal of Hand Surgery (American Volume), Vol. 34, No. 9, 2009, pp. 1605-1611.

[2] “Campbell's: Fracture of Distal Radius: Fracture \& Dis- 
location,” 11th Edition, Mosby Elsevier, 2008, pp. 34413452.

[3] J. Vasenius, “Operative Treatment of Distal Radius Fractures,” Scandinavian Journal of Surgery, Vol. 97, No. 4, 2008, pp. 290-297.

[4] H. J. Kreder, D. P. Hanel, J. Agel, M. McKee, E. H. Schemitsch, T. E. Trumble and D. Stephen, "Indirect Reduction and Percutaneous Fixation versus Open Reduction and Internal Fixation for Displaced Intra-Articular Fractures of the Distal Radius: A Randomised, Controlled Trial," Journal of Bone and Joint Surgery (British Volume), Vol. 87, No. 6, 2005, pp. 829-836.

[5] D. S. Ruch, J. Vallee, G. G. Poehling, et al., “Arthroscopic Reduction versus Fluoroscopic Reduction in the Management of Intra-Articular Distal Radius Fractures," Arthroscopy, Vol. 20, No. 3, 2004, pp. 225-230.

[6] T. Gausepohl, D. Pennig and K. Mader, "Principles of External Fixation and Supplementary Techniques Distal Radius Fractures,” Injury, Vol. 31, Suppl. 1, 2000, pp. 5670. doi:10.1016/S0020-1383(99)00264-8
[7] W. Dee, W. Klein and H. Rieger, "Reduction Techniques in Distal Radius Fractures,” Injury, Vol. 31, Suppl. 1, 2000, pp. 48-55. doi:10.1016/S0020-1383(99)00263-6

[8] J. Bruske, Z. Niedzwiedz, M. Bednarski, et al., "Acute Carpal Tunnel Syndrome after Distal Radius FracturesLong Term Results of Surgical Treatment with Decompression and External Fixator Application," Chir Narzadow Ruchu Ortop Pol, Vol. 67, No. 1, 2002, pp. 47-53.

[9] D. T. Hutchinson, K. N. Bachus and T. Higgenbotham, "External Fixation of the Distal Radius: To Predrill or Not to Predrill," Journal of Hand Surgery (American Volume), Vol. 25, No. 6, 2000, pp. 1064-1068. doi:10.1053/jhsu.2000.17866

[10] H. J. Kreder, D. P. Hanel, J. Agel, et al., “A Randomized Controlled Trial of Closed Reduction and Casting versus Closed Reduction and External Fixation for Distal Radius Fractures with Metaphyseal Displacement but without Joint Incongruity," Orthopaedic Trauma Association 18th Annual Meeting, 13 October 2002. 